\title{
The Utilization of Cellobiose by Verticillium albo-atrum
}

\author{
By J. B. HEALE AND D. P. GUPTA \\ Department of Biology, Queen Elizabeth College, \\ Campden Hill, London W.8
}

(Accepted for publication 26 June 1970)

SUMMARY

\begin{abstract}
$\beta$-Glucotransferase was demonstrated in mycelial extracts and culture filtrates of Verticillium albo-atrum grown on $2 \%$ cellobiose as the sole source of carbon. Analysis of the mycelium indicated relatively large amounts of cellobiose and gentiobiose, as well as small amounts of a series of three oligosaccharides (DP $3,4,5)$ and glucose; the same compounds were detected in the culture filtrate but at much lower concentrations (except for cellobiose) and glucose was barely detectable. Cellobiose phosphorylase was also present in mycelial extracts, and it is suggested that the production of glucose-I-phosphate from the phosphorylytic cleavage of cellobiose and its rapid utilization as a respiratory substrate explains why the fungus grows so much faster on cellobiose than on glucose. The level of these two enzyme systems is considered to be an important factor in controlling the rate of growth. The significance of the formation of oligosaccharides by the transferase system is discussed in relation to cellulose degradation.
\end{abstract}

\section{INTRODUCTION}

Whitney, Chapman \& Heale (I969) have shown that the degradation of cellulose by Verticillium albo-atrum leads to the appearance of relatively large amounts of cellobiose in the culture medium and that no glucose is produced. Three main components with cellulase $\left(C_{\mathrm{x}}\right)$ activity were separated from culture supernatants and characterized according to molecular weight, $\mathrm{pH}$ activity curves and Michaelis constants. Gupta \& Heale (1970) have presented evidence that, apart from being an excellent growth source for this fungus, cellobiose is the specific inducer of $\mathrm{C}_{\mathrm{x}}$. They also found that cellobiose and most other disaccharides were taken up at rates which suggested some special mechanism for utilization as compared with monosaccharides such as glucose. These findings were similar to those obtained by many workers using cellulolytic bacteria, e.g. Cellvibrio gilvus (Hulcher \& King, 1958; Swisher, Storvick \& King, I964). Faster growth on cellobiose than on glucose is usually attributed to a higher yield of energy per molecule of cellobiose utilized as compared with two free glucose molecules. Phosphorylytic cleavage of cellobiose (mediated by cellobiose phosphorylase) yields free glucose and glucose-I-phosphate, the latter being rapidly consumed in the respiration pathway, while the former is utilized only slowly owing to low levels of hexokinase. As far as we are aware, this system has not been investigated in cellulosedegrading fungi such as Verticillium.

The formation of significant amounts of oligosaccharides and polysaccharides in culture filtrates of Verticillium albo-atrum grown on sucrose has been reported by 
Caroselli (1954) and Green (1954). Le Tourneau (I96r) found oligosaccharides up to the hexacompound in the mycelium and culture filtrate of the same fungus grown on glucose, and she suggested that they were formed by a gluco-fructo-transferase. Buston \& Khan (1956) showed that cell-free extracts of Chaetomium globosum when incubated with cellobiose produced glucose, gentiobiose, sophorose and laminaribiose as well as $\beta$-linked trisaccharides. Mandels \& Reese (1960) found glucose, cellobiose and cellotriose in the culture filtrate of Trichoderma viride grown on cellobiose. The significance of the glucotransferase system involved in oligosaccharide formation during cellulose degradation in these organisms has not yet been satisfactorily explained. The present paper deals with the possible role of this enzyme and of cellobiose phosphorylase in the utilization of the major soluble product of cellulose decomposition, i.e. cellobiose, in $V$. albo-atrum.

\section{METHODS}

\section{Transferase activity and the separation of oligosaccharides}

Transferase activity was investigated in mycelial extracts prepared from 14 day cultures grown in modified Dox medium (Gupta \& Heale, 1970) supplemented with $2 \%$ cellobiose. Mycelial mats were harvested by centrifugation at $4500 \mathrm{~g}$, washed with sterile distilled water and extracted by grinding in 0.1 M-phosphate buffer ( $\mathrm{pH} 6 \cdot 0$ ) containing merthiolate (a few drops of a $1 / 1000$ dilution) at $4^{\circ}$ with purified sand (B.D.H.) in a pestle and mortar. The extract was centrifuged at $24,000 \mathrm{~g}$ for an hour at $0^{\circ}$ in a High Speed MSE 18 and the clear supernatant dialysed against $0.0 \mathrm{I} M$ phosphate buffer ( $\mathrm{pH} 6.0$ ) for $24 \mathrm{~h}$. at $4^{\circ}$. The enzyme reaction mixture consisted of $0.3 \mathrm{ml}$. of $0 . \mathrm{I} \%$ cellobiose, $0.3 \mathrm{ml}$. of $0 . \mathrm{I} \%$ glucose plus uniformly labelled D-glucose ${ }^{14} \mathrm{C}(\mathrm{U})$, specific activity $320 \mathrm{mCi} / \mathrm{mm}$, (Radiochemical Centre, Amersham) and $0 \cdot 2 \mathrm{ml}$. of the extract. One drop of merthiolate was added to the mixture, which was incubated at $24^{\circ} \pm \mathrm{I}^{\circ}$. As a control, either $0.1 \mathrm{ml}$. of the phosphate buffer $(0 . \mathrm{I} \mathrm{M})$ or boiled enzyme was used in place of the extract. Fifty $\mu$ l. was removed at intervals of 30,60 , 90, I 20 and I50 min. and applied to Whatman no. I filter paper sheets and chromatographed at room temperature for $20 \mathrm{~h}$. using a solvent system containing $n$-propanol, ethyl acetate and water $(7: 1: 2)$. In addition, glucose and cellobiose (both at $0.1 \%$ ) were incubated separately with the mycelial extract and tested similarly. For reference spots, a mixture of glucose and cellobiose was employed. Chromatograms were dried, sprayed with acetic benzidene and heated at $110^{\circ}$ (Bacon \& Edelman, I951). The location of the sugars separated by chromatography was determined by preparing radioautograms. The activity of each separated sugar was determined by liquid scintillation counting: for this the chromatograms were cut into $2.5 \times 6.0 \mathrm{~cm}$. pieces and each piece was placed around the inner horizontal wall of a scintillation vial together with $\mathrm{I} 5 \mathrm{ml}$. of a solution containing $5 \mathrm{~g}$. of butyl-PBD/l. toluene. For a quantitative determination, similarly chromatographed and dried filter paper pieces containing known amounts of ${ }^{14} \mathrm{C}$ radioactive glucose were employed. Each sample was counted four times for 200 sec. with a Packard Tri-carb scintillation spectrometer. The counting efficiency using this method was found to be $65.5 \%$ and the average mean counts were converted to $\mu \mathrm{Ci}$ per sample. The transferase activity was then expressed in terms of the percentage incorporation of $\mathrm{D}$-glucose ${ }^{14} \mathrm{C}$ into oligosaccharides. In addition, both the mycelial extract and the supernatant were examined chromatographically over the 14 day culture period in order to correlate the results of the in 
vitro assay with the levels of cellobiose and oligosaccharides actually formed during growth.

Cellobiose phosphorylase. Cellobiose phosphorylase activity was investigated in mycelial extracts of the fungus prepared in the same way as described above, except that $0.05 \mathrm{M}-\mathrm{Na}$ citrate buffer was used $(\mathrm{pH} 6.0)$. The reaction mixture consisted of I ml. of buffer containing $100 \mu$ moles cellobiose, $3 \mu$ moles NaF, $4.5 \times 10^{-3} \mu$ moles $\mathrm{MgCl}_{2}$, I $8 \mu$ moles of inorganic phosphate and $\mathrm{I} \mathrm{ml}$. of enzyme preparation (Sato \& Takashi, 1967). One drop of merthiolate was added and the mixture incubated at $30^{\circ}$ for $2,4,6$ and $8 \mathrm{~h}$. As a control, boiled enzyme was used. The reaction was stopped by placing the tubes in boiling water for $5 \mathrm{~min}$. and the disappearance of inorganic phosphate was determined according to a modification of the procedure of Fiske \& Subbarow (1925) using an auto analyser (Technicon). Enzyme activity was expressed as $\mu$ moles of inorganic phosphate consumed in the presence of $\mathrm{I} \mathrm{ml}$. of enzyme preparation. The products of the reaction were analysed by paper chromatography using a pyridine-butanol-water $(2: 3: 1 \cdot 5)$ solvent system. Glucose-I-phosphate was detected by a spray containing $3 \%$ perchloric acid, I \% ammonium molybdate and $0.1 \%$ versene in $0.1 \mathrm{~N}-\mathrm{HCl}$. The chromatogram was air dried before examining the phosphate spots under u.v. irradiation (Hanes \& Isherwood, I949).

The formation of cellobiose from glucose and glucose-I-phosphate as a result of cellobiose phosphorylase activity was also investigated. The reaction mixture consisted of $0.05 \mathrm{ml}$. of $0 . \mathrm{I} \mathrm{M}-\mathrm{MgCl}_{2}, 0.05 \mathrm{ml}$. of $0 . \mathrm{I} \mathrm{M}-\mathrm{NaF}, 0.3 \mathrm{ml}$. of $0 . \mathrm{I} \mathrm{M}$-glucose-Iphosphate, $0.3 \mathrm{ml}$. of $0 \cdot \mathrm{I} \mathrm{M}$-glucose plus uniformly labelled glucose $\left({ }^{14} \mathrm{C}(\mathrm{U})\right)$, specific activity $320 \mathrm{mCi} / \mathrm{mm}$ ), $0.3 \mathrm{ml}$. of $0.05 \mathrm{M}-\mathrm{Na}$ citrate buffer ( $\mathrm{pH} 6.0$ ) and I ml. of enzyme preparation. One $\mathrm{ml}$. of this mixture was placed in each of two tubes; one was immediately immersed in boiling water for $5 \mathrm{~min}$. and served as a control. After addition of merthiolate both tubes were incubated for $8 \mathrm{~h}$. at $30^{\circ}$. Enzyme activity was stopped by placing the tubes in boiling water. The mixtures were brought to room temperature and approximately $50 \mathrm{mg}$. of a I : I mixture of Permutit de-Acidite, FF, SRA 64, anion exchange resin, and Zeocarb 225 SRC I3, cation exchange resin added to each tube. Shaking the tubes with the resin removed'salts that otherwise interfered with chromatographic separation of the sugars. After standing, the supernatant was decanted and $50 \mu \mathrm{l}$. samples were applied to Whatman no. I filter paper sheets. Autoradiograms were prepared as described above. Enzyme activity was expressed as the percentage incorporation of glucose ${ }^{14} \mathrm{C}$ into cellobiose.

\section{RESULTS}

\section{Oligosaccharide formation and transferase activity}

Chromatographic analysis over the growth period showed that both cellobiose and gentiobiose accumulated in large amounts within the mycelium. These substances were not well separated in the solvent system used but could be distinguished by the use of reference markers (cellobiose $\operatorname{Rg} 50$, gentiobiose $\operatorname{Rg} 45$ ). Small amounts of glucose were positively identified by correspondence to a glucose reference. Three oligosaccharides were also detected with Rgs of 35, 23 and 12; they showed a good linear relationship between their logarithmic partition function $\alpha$ (defined as $\log I-\mathrm{Rg} / \mathrm{Rg}$ and molecular size (Chesters \& Bull, I964) assuming them to be of DP 3, 4 and 5 respectively. It was not possible, however, to decide definitely whether they were $\beta$-I,4 or $\beta$-I, 6 linked oligosaccharides. The amounts of oligosaccharides (as measured by their 
benzidene reaction) of $\mathrm{DP}_{3}$ and above decreased with increasing molecular size. Similar compounds were detected in the culture filtrate but at much lower concentrations and glucose was barely detectable.

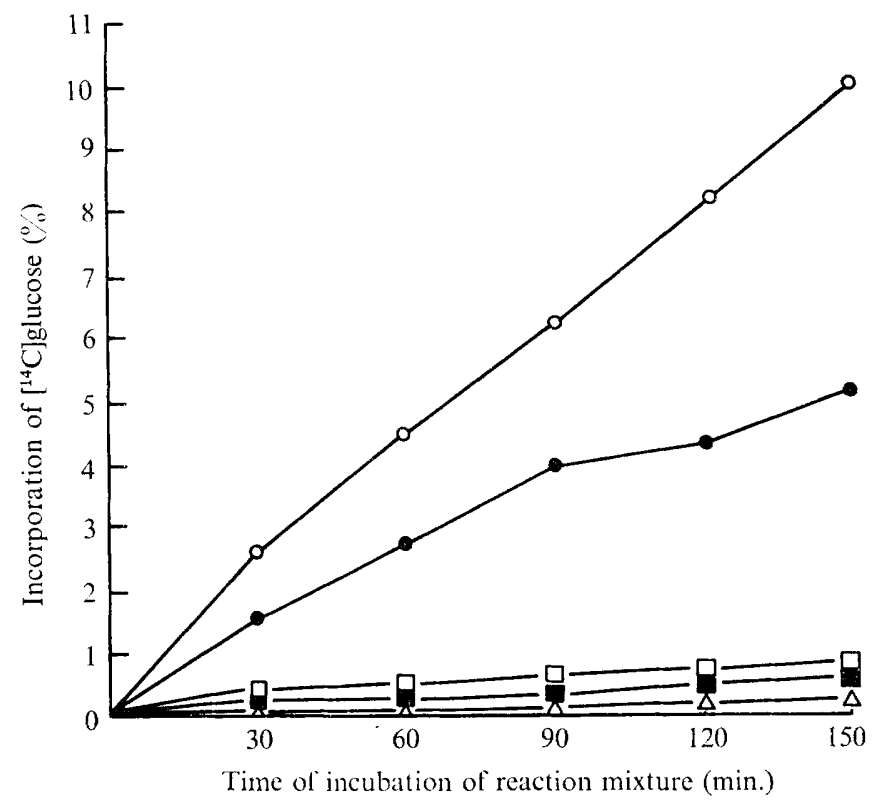

Fig. I. Percentage incorporation of $\left.{ }^{14} \mathrm{C}\right] \mathrm{glucose}$ into various compounds* in the presence of a mycelial extract showing $\beta$-glucotransferase activity. $\mathrm{O}-\mathrm{O}$, Unidentified compound (5); $-\square$, gentiobiose (4); $\square-\square$, gentiotriose (3); $\square-\square$, gentiotetraose (2); $\triangle \longrightarrow \triangle$, gentiopentaose (I).

* The numbers correspond to those numbers on the autoradiograph in Pl. $?$.

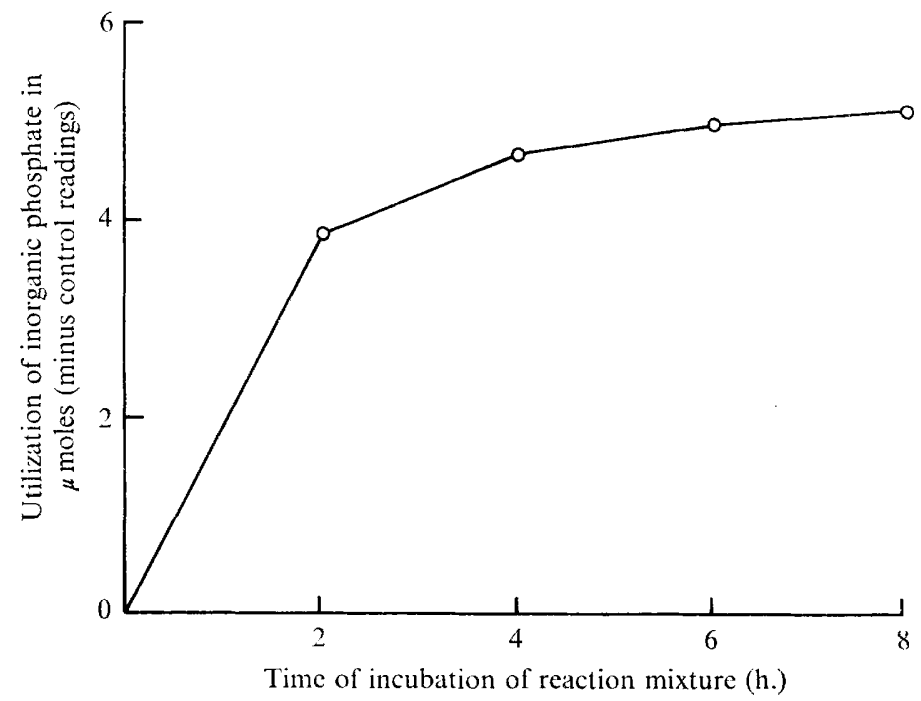

Fig. 2. Utilization of inorganic phosphate in the phosphorylation of cellobiose to glucose-Iphosphate and glucose in the presence of a mycelial extract showing cellobiose phosphorylase activity. 
When cell-free mycelial extracts from I 4 day cultures of the fungus were incubated with a mixture of cellobiose and labelled glucose followed by autoradiography (PI. I), evidence of glucotransferase activity was obtained. Carbon I 4 was rapidly incorporated into two compounds, one of which (spot 4) was identified as gentiobiose; the other compound (spot 5) was of mobility intermediate between cellobiose and laminaribiose and remains unidentified. Three labelled oligosaccharides were also detected (spots 3 , 2, I) and a plot of their logarithmic functions suggested that gentiobiose and these substances were in the same series, i.e. they were gentiodextrins of DP 2 to 5 containing $\beta-\mathrm{I}, 6$ linkages. The extent of incorporation (Fig. I) decreased with increasing DP, possibly reflecting the relative amounts of these oligosaccharides detected in the mycelial analyses. Similar indications of glucotransferase activity were obtained when concentrated culture supernatant (reduced to $\frac{1}{10}$ th volume by dialysis against polyethylene glycol at $4^{\circ}$ ) was used instead of the mycelial extract.

Cellobiose phosphorylase. The rates of utilization of inorganic phosphate (Fig. 2) shown by mycelial extracts suggested a high phosphorylase activity. The production of glucose-I-phosphate and glucose during phosphorylytic cleavage of cellobiose was confirmed by chromatography. When glucose-I-phosphate and glucose with radioactive glucose were incubated with the mycelial extract for $8 \mathrm{~h}$. labelled cellobiose was detected.

\section{DISCUSSION}

The radioactive incubation tests demonstrated $\beta$-glucotransferase activity both in mycelial extracts and, to a lesser extent, in the culture filtrate of Verticillium albo-atrum. The mechanism of formation of labelled gentiobiose is almost certainly one involving direct transfer of the glucosyl moiety from cellobiose to the labelled glucose acceptor and the formation of a $\beta$-I,6 linkage as follows:

(a) Cellobiose + enzyme $\rightarrow$ glucosyl enzyme complex + glucose,

(b) Glucosyl-enzyme complex + labelled glucose* $\rightarrow$ labelled gentiobiose*.

Chesters \& Bull (1964) working with several different fungi reported that glucosyl transfer to the $-\mathrm{I}, 6$ position predominated possibly because of the greater availability of the $-\mathrm{OH}$ group at carbon atom 6 since it lies out of the plane of the hexose ring.

The subsequent transferase reactions are envisaged as follows:

(I) Gentiobiose* + gentiobiose $\rightleftharpoons$ gentiotriose* + glucose,

(2) Gentiotriose* + gentiobiose $\rightleftharpoons$ gentiotetraose ${ }^{*}+$ glucose,

(3) Gentiotetraose* + gentiobiose $\rightleftharpoons$ gentiopentaose* + glucose.

At each of the steps (I) to (3) the gentiobiose involved could be labelled from (a) and (b) so that with increasing times of incubation, the proportion of label in the gentiodextrins increases. At the same time, however, the level of incorporation would decrease with DP. The analysis of the mycelial extracts confirmed that cellobiose and gentiobiose were present in large amounts but synthesis of gentiodextrins of $\mathrm{DP}_{3}$ and above is less important. There also seems to be slight transferase activity in the culture supernatant which explains why some oligosaccharides are formed there (Caroselli, I 954; Green, 1954; le Tourneau, 196I), but whether extracellular transferase plays any part in cellulose utilization is problematical.

The high cellobiose phosphorylase activity demonstrated in the present work may help to explain why cellobiose is a much better carbon source for growth than is glucose for this fungus. The production of glucose-I-phosphate which can be readily utilized in the respiration pathway as already suggested in Cellvibrio gilvus and other 
cellulose-decomposing bacteria (Hulcher \& King, 1958; Swisher et al. 1964) could be the important factor here.

The levels of the phosphorylase and the transferase systems, must play an important part in controlling the rates of growth and cellulose degradation. It has already been established (Whitney et al. 1969; Gupta \& Heale, 1970) that exogenous cellobiose induces the production of three major extracellular cellulase $(\mathrm{Ca}) \mathrm{com}$ ponents. These components mediate the degradation of $\beta-\mathrm{I}, 4$ linked cellulose chains to cellobiose units. Once inside the mycelium cellobiose can be metabolized by at least two reactions: in the first, cellobiose phosphorylase cleaves the disaccharide producing glucose phosphate; alternatively, transferase reactions outlined above result in the formation of gentiobiose and $\beta-1,6$ linked gentiodextrins. The phosphorylase system would overcome any 'metabolic bottleneck' caused by the lack of a cellobiase (Whitney et al. 1969) so perhaps it is best to regard the production of gentiodextrins as a mechanism for maintaining a pool of relatively simple carbon compounds that could be utilized if cellobiose uptake becomes limiting, i.e. when the cellulose substrate is depleted.

The authors wish to thank Professor J. Edelman, Dr J. Chapman and Dr A. Bull for valuable discussion and advice during this work, and Mr Clive Daws for technical help.

Thanks are also due to the University of Ranchi, Bihar, India, for allowing study leave to D. P. G.

\section{REFERENCES}

Bacon, J. S. D. \& Edelman, J. E. (I95I). The carbohydrates of the Jerusalem artichoke and other compositae. Biochemical Journal 48, I I4-I 26.

Buston, H. W. \& Khan, A. H. (1956). The production of $\beta$-linked glucose saccharides from cellobiose by Chaetomium globosum. Biochimica et Biophysica Acta 19, 564-565.

Caroselli, N. E. (1954). Polysaccharides produced in vitro by Verticillium albo-atrum. Dissertation Abstracts 14, 2186-2187.

Chesters, C. G. C. \& Bull, A. T. (1964). Transglucosylase activity of fungal laminarinases. Nature, London 202, 454-465.

Fiske, C. H. \& SubBarow, Y. (I925). The colorimetric determination of phosphorus. Journal of Biological Chemistry 66, 375-400.

GREEN, R. J. (1954). A preliminary investigation of toxins produced in vitro by Verticillium alboatrum. Phytopathology 44, 433-437.

Gupta, D. P. \& Heale, J. B. (1970). Induction of cellulase $\left(\mathrm{C}_{\mathbf{x}}\right)$ in Verticillium albo-atrum. Journal of General Microbiology 63, 163-173.

HANES, C. S. \& Isherwood, F. A. (1949). Separation of the phosphoric esters on the filter paper chromatogram. Nature, London, 164, I107-I I 2.

Hulcher, F. J. \& KING, K. W. (1958). Metabolic basis for disaccharides preference in a Cellvibrio. Journal of Bacteriology 76, 57I-577.

Le Tourneau, D. (I96I). Oligosaccharides production from sucrose by Verticillium albo-atrum. Plant Physiology 36, 102-104.

Mandels, M. \& Reese, E. T. (1960). Induction of cellulase in fungi by cellobiose. Journal of Bacteriology 79, 816-826.

SATo, M. \& TAKAHASHI, H. (1967). Fermentation of $\mathrm{C}^{14}$-labelled cellobiose by Cellulomonas fimi. Agricultural and Biological Chemistry, Tokio 3r, 70-74.

Swisher, E. J., STORvick, W. O. \& KING, K. W. (1964). Metabolic nonequivalence of the two glucose metabolites of cellobiose in Cellvibrio gilvus. Journal of Bacteriology 88, 81 7-820.

Whitney, P., Chapman, J. M. \& Heale, J. B. (1969). Carboxymethycellulase production by Verticillium albo-atrum. Journal of General Microbiology 56, 2 I 5-225. 


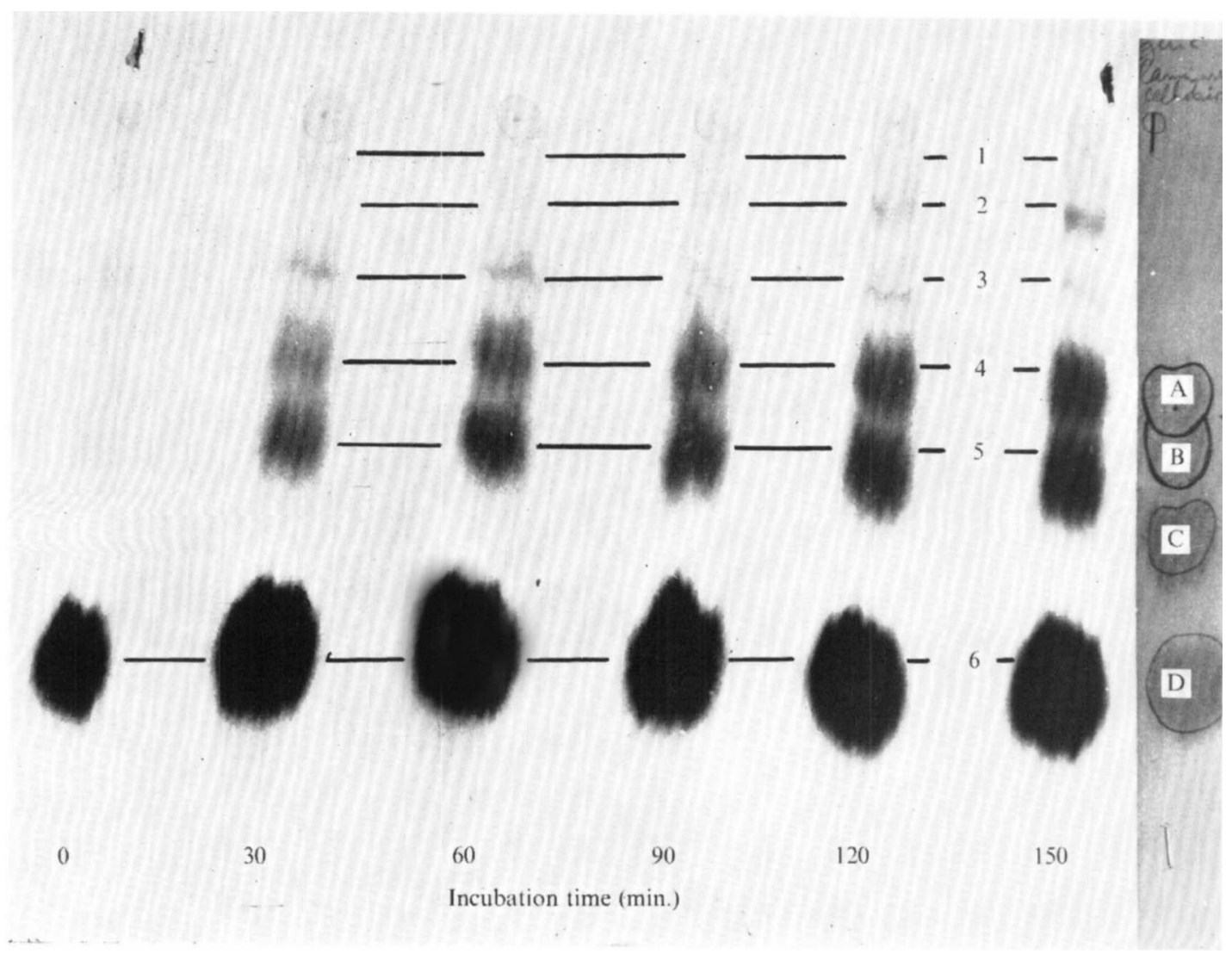




\section{EXPLANATION OF PLATE}

Autoradiograph showing increasing incorporation of $\left[{ }^{14} \mathrm{C}\right]$ glucose label into various oligosaccharides during incubation of a mycelial extract of Verticillium albo-atrum showing $\beta$-glucotransferase activity. A benzidene-sprayed chromatograph strip is shown on the right with several reference compounds: A, gentiobiose; B, cellobiose; C, laminaribiose; D, glucose. Tentative identifications (see text) of labelled compounds: I, gentiopentaose; 2, gentiotetraose; 3, gentiotriose; 4, gentiobiose; 5, unidentified oligosaccharide; 6 , glucose. 